\title{
The Construction of Flipped Classroom Teaching Model in Interpreting Teaching for English Majors
}

\author{
Huan $\mathrm{Yu}$ \\ School of Foreign Languages of China West Normal University, \\ Nanchong, 637009, China
}

\begin{abstract}
In the field of interpreting teaching for English majors, the traditional teaching model has been unable to adapt to the needs of the new era and a new teaching model is urgently needed. With the rapid development of the information technology, the flipped classroom teaching model has been applied in many disciplines in recent years and its emergence also provides a new idea for the innovation of the interpreting teaching for English majors. In order to solve many problems of the traditional interpreting teaching model, the author designed a new study on the content system, the task system, the skill system as well as the evaluation system in interpreting teaching of English majors based on the concept of flipped classroom, and constructed the flipped interpreting teaching model to improve students' interpreting ability, which could also provide an effective way to optimize the interpreting teaching effect for English majors.
\end{abstract}

Keywords-Interpreting Teaching; Flipped Classroom; English Majors; Construction

\section{INTRODUCTION}

With the increase of international communication, the demand for English interpreters is also on the rise. As an important course in the training process of English translators, the interpreting course is also difficult for students to learn. Students lack the solid foundation of language, proficiency in interpreting skills, proper interpreting training, excellent psychological quality and appropriate professional qualifications, thus losing their interest in interpreting learning. Teachers have also encountered many problems such as limited teaching time, limited teaching environment, a single boring teaching model, and the lack of systematic and scientific evaluation system. In recent years, the flipped classroom teaching model in high school teaching in the United States has drawn the attention of scholars and has been widely used in many disciplines [1]. The author tries to apply the concept of flipped classroom in the interpreting teaching to English majors, design a new study on the content system, the task system, the skill system as well as the evaluation system of interpreting teaching, and finally construct the flipped interpreting teaching model in order to promote the reform of traditional interpreting teaching model for English majors and cultivate qualified interpreters who could meet the needs of the times.

\section{The EnLightenment of FlipPed Classroom to INTERPRETING TEACHING}

\section{A. The Cognition of the Nature of Flipped Classroom}

The reason why flipped classroom is respected by experts in education at home and abroad has an essential relationship with which is more in line with the law of education and teaching. Quilina, a well-known person in the western education circles, put forward that the process of acquiring new knowledge of mankind ultimately needed to go through his own practice. In order to carry out this kind of practice,people need to grasp the objective law. The traditional teaching model ignores the practicality of human learning, while the flipped classroom teaching model can greatly stimulate students' curiosity and enable them to carry out various learning activities more joyfully. The essence of flipped classroom is to cultivate the students to acquire what they need through practice or training. Through independent learning and cooperative exploration, learners can master the relevant laws more quickly, and can truly become the regulators and managers of self-learning. The flipped classroom teaching model conforms to the cognitive law of the learners, which can save teaching resources and improve teaching efficiency.

\section{B. Problems in Interpretation Teaching for English Majors}

In recent years, English majors in many universities have set up the interpreting course, which has become one of the main forces of training interpreting talents. As a major course to cultivate practical skills, most universities only offer one year's interpreting course, usually once a week with insufficient total class hours and teaching time, which makes it very difficult for students to master interpreting skills in a short period. In addition, in the traditional interpreting teaching model, the teacher's role is mainly to impart of interpreting knowledge and skills. Teachers should teach textbook knowledge to students in limited time, the teaching form is single and boring, and students would naturally focus on theoretical knowledge. Due to the limited conditions, students cannot conduct sufficient and real-time interpreting training in the classroom, and lack opportunities for interpretation training. Even if they have a chance to speak English, because of poor psychological quality, they could not accomplish their task and could not achieve the goal of the practice. Therefore, teachers cannot guide students in time, 
resulting in failing to reach the goal of interpreting teaching. What's more, Students have different levels of the language knowledge, the cultural knowledge and interpretation skills, and these factors become one of the limitations of the cultivation of interpreting talents in English majors.

\section{The Significance of the Application of Flipped Classroom in Interpreting Teaching}

With the advent of the digital age, the development of educational technologies, the maturity of social networks, and the sharing of educational resources, all these factors allow teachers to use new teaching methods that were previously unavailable. The implementation process of the flipped classroom teaching model is to help teachers to solve these problems such as the lack of teaching time, the insufficient interpreting practice in the classroom, the single and boring teaching form and teaching environment. Students become the real subject in the flipped classroom. The change of the teaching form can arouse students' interest in learning, so as to bring students' subjective initiative into full play. The flipped interpreting teaching can help teachers to build simulated interpreting practice for learners and create an atmosphere of interpreting scene to help students improve the psychological quality and adaptability of interpreting [2]. In addition, teachers can give timely and direct guidance to make the practice more effective. The contents of classroom teaching are no longer dominated by theoretical studies, but mainly are the interpreting activities related to market and social needs. The use of multiple evaluation mechanisms in interpreting classrooms, such as students' self-assessment mechanism, students' mutual evaluation mechanism, and the comment mechanism and so on can help students experience the professional features of interpreting, improve the quality of interpreting teaching and cultivate high-quality professional interpreters.

\section{The Construction of Flipped Classroom Model in INTERPRETING TEACHING FOR ENGLISH MAJORS}

\section{A. The Creative Design of the Content System in Interpreting Teaching}

Students' self-learning ability is crucial in the flipped classroom teaching model. Before designing the teaching contents, teachers should firstly have a comprehensive understanding of students' abilities at different levels, and then design teaching contents that meets different needs of students in terms of themes and interpreting skills. Secondly, teachers should advance many kinds of learning resources, such as micro-class videos, teaching courseware and learning websites, to the online learning platform in advance to facilitate students to before -class self-learning and after-class training. At the same time, teachers also need to grasp the difficulty of knowledge points, pay attention to the fun of learning materials and the length of video lessons, and make students easily accept them in self- learning, the review and the training, which will not make students feel tired in the learning process. In order to well motivate students to learn before class and to stimulate their thirst for knowledge, teachers can design some questions and control the progress and the effect of students' learning through their answers online.

\section{B. The Creative Design of the Task System in Interpreting Teaching}

The task system of the flipped classroom teaching model mainly includes the pre-class interpreting teaching task, the in-class interpreting teaching task and the after-class interpreting teaching task. The teacher firstly arranges the pre-class tasks, and then students independently carry out these tasks and learn the interpreting knowledge and skills with the help of interpreting data, micro-classes and websites, and finally find relevant problems in the learning feedback process. In order to solve these problems, teachers and students can conduct face-to-face cooperation. In the classroom, teachers can use interpreting resources, teaching courseware and teaching videos,such as news videos, interview videos, financial negotiation videos, culture and education videos, technology information videos and so on, to enable students to acquire and internalize relevant interpreting knowledge and skills through students' interaction and the teacher's reviews. Teachers can also arrange post-class assignments,so that students can consolidate the knowledge and skills acquiring in the classroom through repeated exercises. Through the design of the thematic simulation training, teachers can make students familiar with a wide range of interpreting materials as well as diverse cultural backgrounds throughout the course of interpreting learning and finally build a perfect interpreting knowledge system [3]. This teaching task system solves the problem of insufficient teaching time in the traditional interpreting teaching, forms an innovative teaching model including the pre-class self-learning process of interpreting knowledge and skills, the in-class internalization process of interpreting knowledge and skills and the post-class consolidation and optimization process of interpreting knowledge and skills. It also realizes a hybrid learning model that combines online interaction and practical exchange between teachers and students. (Figure 1) 


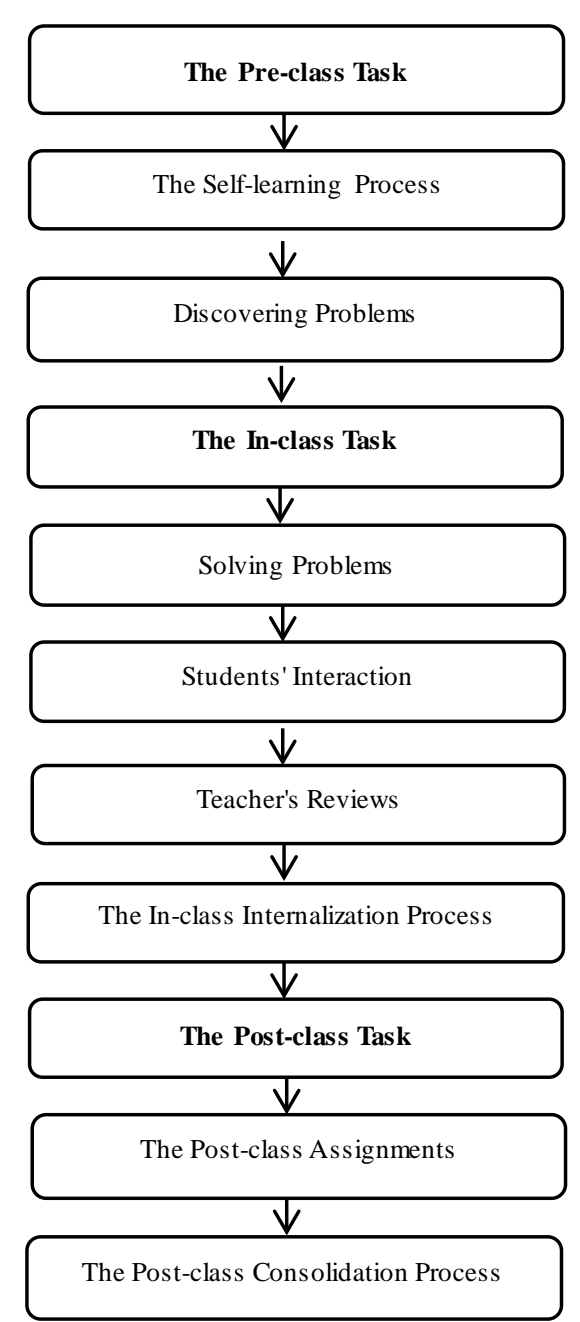

Fig. 1. The creative design of the task systembased on Flipped Classroom

\section{The Creative Design of the Skill System in Interpreting Teaching}

The Interpreting skill training is the focus in the interpreting teaching, including listening skills, preparation skills, memory skills, speech genre analysis skills, figures interpreting skills, public speaking skills, target language expression skills and coping tactics. The Interpreting teaching based on the flipped classroom model focuses on the training of some of these skills, such as listening skills, memory and note-taking skills, target language expression skills and intercultural communication skills. It is worth noting that the training of students' public speaking ability and psychological quality should always run through the whole teaching process [4]. The interpreting skill system based on the concept of the flipped classroom model enables students to control the progress of interpreting skills learning independently, greatly enhances the exchange opportunities, students' comprehensive interpreting ability and psychological quality, which effectively makes up for shortcomings and constraints existing in the traditional interpreting skill teaching, truly realize the "student-centered" teaching goal, and thus transform their interpreting learning concepts, as well as cultivate their lifelong interpreting learning habit and ability.

\section{The Creative Design of the Evaluation System in Interpreting Teaching}

The interpreting evaluation system is an important part of the flipped interpreting teaching model, which can timely monitor and evaluate teaching activities, teaching tasks and the teaching process in and out of class, and can judge the status of individuals and groups in the flipped interpreting teaching in the classroom timely with an objective evaluation [5]. The evaluation contents of interpreting teaching based on the flipped classroom model should be diversified, including interpreting theories, the listening ability, the bilingual conversion ability, interpreting skills, the public speaking ability, the intercultural communicative competence and the psychological quality. The process of interpreting evaluation system is actually a step-by-step process from the evaluation of interpreting knowledge to the evaluation of interpreting ability, and finally to the evaluation of interpreters' comprehensive application ability. In the flipped interpreting teaching model, the diversity of evaluation objects should also be realized, which is mainly reflected in the evaluation of individuals and groups of students in and out of class, in the mutual assessments of student groups, in students 'evaluation on teachers and themselves as well as on teaching methods, teaching contents, and the teaching process. Through online and face-to-face communication in the classroom, the teacher's assessments of students can make students understand their current learning status objectively and clearly, and make corrections and improvements in a targeted manner. At the same time, peer assessments between student groups can create a competitive and progressive learning environment and foster the team spirit of mutual assistance and cooperation. Therefore, the diversification of interpreting evaluation objects can make the evaluation system show a benign cycle of development. In a word, the design of interpreting evaluation system focuses on teachers' continuous and effective multidimensional evaluation of students in the flipped interpreting teaching model.

\section{CONCLUSION}

As a new teaching concept, the emergence of the flipped classroom model has a catalytic effect on the interpreting teaching reform for English majors. The flipped classroom teaching model, in which students can arrange the learning time and progress according to their own situation, focuses on individual differences and provides students with active learning and cooperative discussion opportunities, imperceptibly cultivating students' comprehensive abilities, such as self-learning, speculation and innovation. Meanwhile, this new teaching model also transforms the roles between teachers and students. In the classroom teachers will change the role from the traditional imparter of knowledge into a learning facilitator, and students transform from the passive recipients into the main researcher [6]. What's more, the diversified and comprehensive evaluation system can effectively monitor students' learning effect online, in and out of class, which is beneficial to improve the quality of interpreting practice. In view of the continuous development 
of flipped classroom and the increasing demand for English interpreting talents in modern society, the interpreting teaching model based on the concept of flipped classroom for English majors urgently needs further researches.

\section{ACKNOWLEDGMENT}

This research was financially supported by Fundamental Research Funds of China West Normal University (Project No. 17D046).

\section{REFERENCES}

[1] Jonathan Bergmann, Aaron Sams, Flip Your Classroom: Reach Every Student in Every Class Every D. Washington DC: International Society for Technology in Education,2012, pp.5-30.

[2] Wang Honglin, "A study of interpreting teaching action based on 'flipped classroom'," Chinese Translators Journal. China, vol. 36, pp.59-62, February 2015.

[3] Lu Jing, Yi Long, "Application of flipped classroom in interpreting class," China Education of Light Industry. China, vol. 3, pp.50-52, June 2016.

[4] Wang Jianna, "On major English interpretation instructed in the flipped classroom model," Journal of Ningbo University (Educational Science Edition). China, vol.5, pp.114-118, September 2016.

[5] Chen Sheng bai, An Ecological Approach to Interpretation Studies, Shanghai: Fudan University Press, 2013, pp.160-162(In Chinese).

[6] Dan Berrett, " How 'flipping' the classroom can improve the traditional lecture," The Chronicle of Higher Education. Washington DC, vol. 12, pp.1-14, February 2012. 